\title{
Empirical Research on Military Ethical Behaviour
}

\author{
Deanna L. Messervey and Erinn C. Squires
}

\section{Contents}

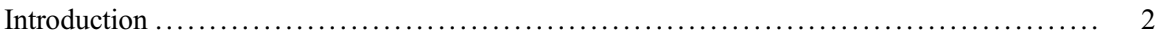

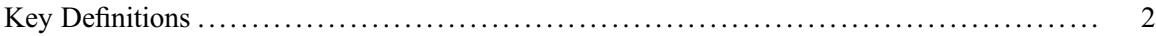

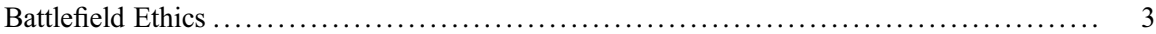

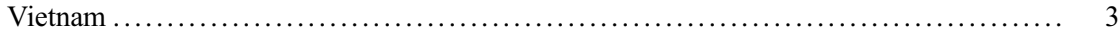

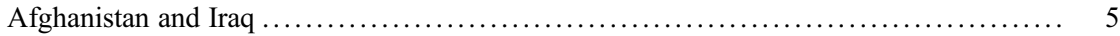

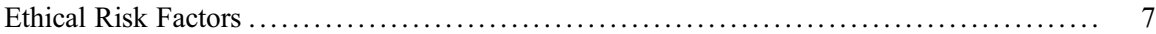

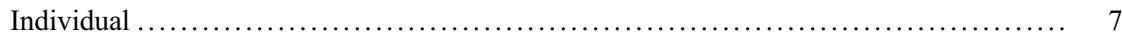

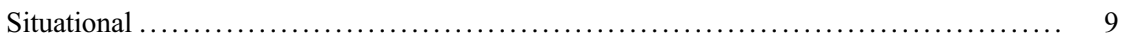

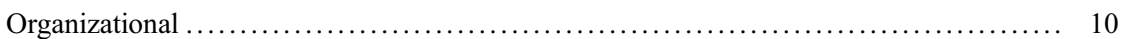

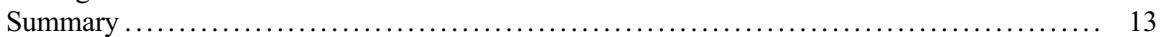

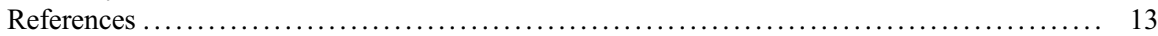

\section{Abstract}

This chapter presents an overview of key empirical research examining ethical and unethical behaviour in the military. Early research examined the impact of atrocities on the psychological well-being of Vietnam War veterans. In later conflicts, researchers examined battlefield attitudes, behaviours, willingness to report fellow unit members for ethical violations, and the adequacy of training. In addition to battlefield ethics, researchers have also investigated individual, situational, and organizational factors that increase the risk of unethical behaviour (i.e., ethical risk factors). This chapter summarizes research that highlights how individual differences in moral identity and malevolent traits can impact ethical and unethical behaviour among military personnel. It also discusses how situational factors, such as sleep deprivation and anger, can increase the likelihood of military personnel engaging in unethical behaviour. Lastly, the chapter discusses

D. L. Messervey $(\bowtie) \cdot$ E. C. Squires

Department of National Defence, Ottawa, ON, Canada

e-mail: Deanna.Messervey@forces.gc.ca; Erinn.Squires@forces.gc.ca 
how organizational factors, such as ethical climate and culture and ethical leadership, play a role in ethical and unethical behaviour.

\section{Keywords}

Atrocity $\cdot$ Abusive violence $\cdot$ Ethical behaviour $\cdot$ Unethical behaviour $\cdot$ Ethical risk

\section{Introduction}

Torture, mutilation, rape, and genocide have long been part of armed conflict (Fiske and Rai 2015). Yet warfare has also had guiding principles and customs that would eventually become the Law of Armed Conflict (LOAC) and the Geneva Conventions (International Committee of the Red Cross 2004). Ethical behaviour in general is important for military personnel because of the physical and psychological consequences for the victims, the witnesses, the perpetrators, and for the success of the mission (Blanc et al. 2018). It is therefore important to understand the causes of unethical behaviour among military personnel. This chapter describes the research on ethical behaviour in the military. Drawing heavily on research that measures behavioural outcomes, this chapter begins by discussing research related to battlefield ethical behaviour from the Vietnam War to the present. Next, it presents an overview of individual, situational, and organizational ethical risk factors relevant to the military that have been found to predict ethical behaviour. Although military ethics crosses many disciplines, including philosophy, theology, sociology, and law, this chapter focuses on evidence-based psychological studies of military ethical behaviour and does not address what military personnel ought to do.

\section{Key Definitions}

Many militaries have regulations and directives that set high standards of professional conduct for military personnel backed by serious penalties for not living up to them. Canadian military personnel have a legal obligation to report their peers for unethical behaviour (Queen's Regulations and Orders), for example, and adultery is considered illegal under the American Uniform Code of Military Justice. Moreover, military personnel are bound by the LOAC, which is a set of internationally agreed upon rules that outline who is protected from armed conflict (e.g., wounded soldiers, prisoners of war, civilians) and what forms of warfare are prohibited (e.g., poison; International Committee of the Red Cross 2004). Many of the principles in the LOAC have been ratified by the 1949 Geneva Conventions by Member States of the United Nations, and serious breaches of the Geneva Conventions are considered war crimes (United Nations Office on Genocide Prevention and the Responsibility to Protect, n.d.). 
Although there is no single agreed upon definition of unethical behaviour, this chapter follows Blanc et al. (2018) in defining unethical behaviour as actions inconsistent with the LOAC or military values. Ethical risk is defined as the probability of military personnel acting in ways that are inconsistent with military values, and ethical risk factors are defined as situational, organizational, and individual factors that can influence the likelihood of unethical behaviour (Messervey and Lavergne 2016). Ethical behaviour is understood to span a spectrum from minor transgressions like taking extended breaks to atrocity - "excessive violence and cruelty that does not provide a tactical advantage in war" (Blanc et al. 2018, p. 250). The term abusive violence is often used interchangeably with the term atrocity, and it is defined as inhumane treatment of civilians and prisoners of war and the use of cruel weaponry (Laufer et al. 1984). This definition does not address ethical dilemmas military personnel may face, such as behaviour by personnel in allied nations that violates Western norms.

\section{Battlefield Ethics}

Although researchers were studying the psychological effects of war during World Wars I and II, they only began scientifically examining the psychological effects of witnessing or participating in atrocities or abusive violence during the Vietnam War (Laufer et al. 1984; Wilson and Krauss 1983). Understanding the link between mental health and battlefield ethics surged with more recent wars in Iraq and Afghanistan. In this section, empirical research on military ethical behaviour is summarized, specifically in relation to battlefield ethics since the Vietnam War.

\section{Vietnam}

On March 16, 1968, a Vietnamese hamlet called My Lai was the scene of one of the worst atrocities carried out by American military personnel against civilians. Believing that they were in a search and destroy mission for Viet Cong enemy fighters, soldiers found and shot civilians ranging from infants to the elderly. Many Vietnamese lives were saved when a US helicopter pilot named Hugh Thompson Jr. positioned himself between his fellow US military personnel and the Vietnamese civilians and ordered them to stop killing civilians.

Although the My Lai massacre was the most infamous case of unethical behaviour that took place in Vietnam, it was not the only one. Many believe that the Vietnam War was a "relatively unique war in that its distinctive environmental conditions provided many situational inducements to behave in inhumane ways" (Kraus 2013, p. 3). One of the metrics of military success used in the Vietnam War, for example, was body count (i.e., the number of dead) and those killed by American military personnel were often categorized as a Viet Cong (Kelman and Hamilton 1989). 
In the 1980s, researchers began looking at the link between atrocity and psychological well-being (Laufer et al. 1984; Laufer et al. 1985; Kulka et al. 1988; Wilson and Krauss 1980). In one of the earliest quantitative studies of the link between types of war zone experiences and their psychological consequences, Laufer et al. (1984, 1985) found that traditional combat experiences (e.g., threats to one's personal safety, seeing dead bodies) yielded different psychological outcomes than witnessing and participating in abusive violence, a finding that was supported by later research (King et al. 1995). Laufer used the term abusive violence to refer to excessively violent and brutal conduct during war that included the torture, rape, and killing of civilians, the torture of prisoners of wars, and the mutilation of dead enemy combatants' bodies.

Other early abusive violence (atrocities) research was based on the atrocity exposure subscale of the Vietnam Era Inventory developed by Wilson and Krauss (1983). Although other researchers went on to develop atrocity measures (Breslau and Davis 1987; MacNair 2002), the measures developed by Laufer and colleagues and Wilson and Krauss had the most impact on later atrocity research that focused on American Vietnam veterans. For example, the National Vietnam Veterans Readjustment Study (NVVRS) - a comprehensive US Congress-mandated study that sought to understand the prevalence of PTSD among Vietnam veterans - was built on the work of Laufer and colleagues (Kulka et al. 1988). The NVVRS database influenced later battlefield ethics research (Currier et al. 2014; Fontana and Rosenheck 1993; MacNair 2002). Similarly, a recent study by Dennis et al. (2017) on the link between atrocity and PTSD administered the atrocity subscale developed by Wilson and Krauss (1983).

Four key findings emerged from the Vietnam battlefield ethics research. First, combat exposure predicts abusive violence, such that higher levels of combat exposure are related to greater abusive violence (Blanc et al. 2018; Hiley-Young et al. 1995; Warner et al. 2011; Wilk et al. 2013). Second, many Vietnam veterans were exposed to atrocities, either in the form of witnessing or participating in atrocities and abusive violence. Third, exposure to atrocity increased the risk of psychological disorders, particularly PTSD (Beckham et al. 1998; Breslau and Davis 1987; Dennis et al. 2017; Hiley-Young et al. 1995; Holowka et al. 2012; King et al. 1995). In one early study, researchers found that Vietnam veterans who had PTSD were more likely than Vietnam veterans who did not have PTSD to have witnessed or participated in abusive violence (Shaw et al. 1987). More recently, Dennis et al. (2017) found that exposure to atrocities was associated with PTSD and depression and that atrocity exposure almost completely accounted for the relationship between combat exposure and PTSD. In addition, they found that exposure to atrocity predicted guilt, hostility, depression, and thoughts of suicide. Fourth, participation in atrocity appears to yield more negative psychological outcomes than witnessing atrocity (Breslau and Davis 1987; Hiley-Young et al. 1995; MacNair 2002). Among veterans seeking treatment at a Veterans Affairs center, participation in atrocities significantly increased the risk of PTSD, whereas those who only witnessed atrocities had the same risk of PTSD as those who had not participated in or witnessed atrocities (Breslau and Davis 1987). 


\section{Afghanistan and Iraq}

While there have been incidents of unethical behaviour in the militaries of various countries, including allegations of sexual misconduct among senior military leaders in the Canadian Armed Forces and unlawful killings by members of the Australia Defence Forces, Royal Marines, and the US Marine Corps, much of the available research has been conducted in the United States, especially after the Mental Health Advisory Team (MHAT)-IV was established in response to events within the US military (e.g., at Abu Ghraib). This next wave of battlefield ethics research drew heavily on military personnel who served in the US Operation Enduring Freedom (OEF) in Afghanistan and Operation Iraqi Freedom (OIF) in Iraq. Multiple highprofile incidents of unethical behaviour that violated the LOAC were reported during these operations, including the videotaped killing of a wounded Iraqi insurgent in a mosque by an American marine, the abuse of detainees at Abu Ghraib prison by American reservists, and the alleged unlawful killings of civilians by Australian Special Operations and American military personnel.

\section{The Mental Health Advisory Team (MHAT)}

The US Army chartered a Mental Health Advisory Team (MHAT) in July 2003 to assess the mental health and well-being of soldiers (MHAT I). MHAT's assessment tool became known as the MHAT survey (or the MHAT), which was administered annually to in-theater army personnel and, in 2006, to US Marines as well. The MHAT IV (2006) was expanded to include questions related to battlefield ethics, such as attitudes, behaviours, willingness to report, and training. Key findings from this research revealed a strong connection between unethical behaviour and attitudes among personnel and their mental health. Personnel screened as having mental health issues (e.g., anxiety, depression) were twice as likely as those who did not to report engaging in unethical behaviour. Moreover, personnel who had high levels of anger were more likely than those with low levels of anger to engage in unethical behaviour. Combat experience - measured by having a member of one's unit being a casualty of war and handling dead bodies and human remains - was also related to unethical behaviour. For example, marines who had handled dead bodies were more likely than those who had not to insult or curse at noncombatants, unnecessarily damage private property, and hit or kick a noncombatant.

The MHAT IV was one of the first investigations to report on the ethical attitudes and behaviours of military personnel toward insurgents and noncombatants, and it revealed that many marines and soldiers had attitudes inconsistent with the US military's expectations and standards. In particular, roughly $40 \%$ of soldiers and marines agreed that torture should be allowed in order to save the life of another soldier, and less than half believed that noncombatants should be treated with dignity and respect. Almost a third of respondents reported that they had cursed at or insulted noncombatants and roughly $10 \%$ reported mistreating noncombatants by damaging property or hitting and kicking them. Moreover, less than half of respondents were willing to report a team member for various ethical violations. 
In 2007, the same four dimensions of battlefield ethics (i.e., attitudes, behaviours, willingness to report, and training) were readministered in the MHAT V (2008). Overall, the pattern of findings in MHAT V was the same as those in MHAT IV, with one exception. Soldiers were less likely to report that they had modified the rules of engagement in the MHAT V. The MHAT V also found that deployment length was related to unethical behaviour: Unethical behaviour increased linearly over the first 10 months of the deployment, and then decreased. Building on the results of the MHAT V that showed aggression, combat experience, and PTSD were related to unethical conduct, Wilk et al. (2013) examined the relationship between these variables further. They found that PTSD was not the most important factor in predicting unethical conduct. Rather, unethical conduct was more associated with witnessing atrocities than with PTSD, killing others, and exposure to the death and injury of others.

A key recommendation of the MHAT IV was to implement a battlefield ethics training program. In response, a scenario-based in-theater ethics training program was developed for American soldiers and subsequently assessed. Warner et al. (2011) used the MHAT V battlefield ethics survey results as a baseline and administered these items following the training. They found that attitudes toward the treatment of noncombatants and willingness to report fellow unit members for ethical violations were more aligned with Army standards and the LOAC. Most importantly, Warner et al. (2011) found a decrease in some reported unethical behaviour during deployment.

Much of the research discussed so far has focused on the United States because ethical behaviour research originated out of American involvement in the Vietnam War and again later in MHAT's battlefield ethics research, which focused on US military personnel. Other militaries have since examined battlefield ethics in relation to ethical attitudes and intentions. The Canadian Armed Forces examined the impact of rank on ethical attitudes and intentions and found that ethical attitudes increased as rank group increased (Therrien and Messervey 2019). This pattern of findings is consistent with Dutch qualitative and quantitative research that found that leaders at the officer and noncommissioned member level were more likely than their followers to have more developed moral identities, making them more inclined to discuss moral values and principles when describing morally challenging situations on deployment (De Graaff et al. 2020). In addition, the MHAT battlefield ethical attitudes and behaviour measures were recently administered to Swedish peacekeepers deployed to Mali. The results revealed that no peacekeepers had unnecessarily kicked or hit noncombatants and almost nobody had unnecessarily damaged private property (Lindén et al. 2019). The Dutch Ministry of Defence has also examined the role of moral emotions in morally challenging situations on military operations (De Graaff et al. 2015; Schut et al. 2015). Based on anthropological and psychological research methods, they found that deployment can present morally challenging situations that invoke strong emotions and behavioural response strategies, such as when Dutch values clash with local customs and traditions.

Ethical breaches on the battlefield have also informed research by militaries and academics exploring potential ethical risk factors for unethical behaviour. For 
example, moral courage (having the strength of character to act ethically), moral efficacy (a person's confidence in their ability to behave ethically when faced with a moral challenge), and moral ownership (feeling responsible to act) have each been found to be negatively associated with soldiers' tolerance for torture and for mistreating combatants and noncombatants, and positively related to adherence to Army values and intentions to report others for unethical behaviour (Schaubroeck et al. 2010, as cited by Hannah and Avolio 2010). The following section delves deeper into individual, situational, and organizational risk factors for ethical and unethical behaviour beyond the battlefield.

\section{Ethical Risk Factors}

The key studies described above examine the link between battlefield ethics and behaviour among serving military personnel or veterans. In tandem with the battlefield ethics research, academic and applied researchers have examined various factors that increase or decrease the likelihood of unethical behaviour (i.e., ethical risk factors). Building on Bradley and Tymchuk's work on ethical risk $(2013,2016)$, this section examines three levels of ethical risk: individual, situational, or organizational.

\section{Individual}

Ethics research on individual differences is generally grouped into two categories. The first looks at individual differences that increase ethical behaviour, such as moral identity. The second looks at individual differences that increase unethical behaviour, such as malevolent traits. Other individual risk factors include moral efficacy (Hannah et al. 2011), self-control (Baumeister and Alghamdi 2015), and how well one's values fit with those of the organization (Vila-Vázquez et al. 2021).

\section{Moral Identity and Ethical Behaviour}

Moral identity - the extent to which having moral traits, goals, and values are central to one's self-concept - is an individual difference that predicts ethical behaviour (Aquino and Reed 2002). People higher in moral identity are more likely than those who have a lower moral identity to volunteer, avoid acting aggressively, and to engage in behaviours that exceed their required job duties (Hertz and Krettenauer 2016). The Moral Identity Scale developed by Aquino and Reed (2002) is the most frequently used measure moral identity (Hertz and Krettenauer 2016; Jennings et al. 2015). A key finding in the moral identity research is that people's moral identities need to be activated to guide behaviour. For example, recalling the Ten Commandments activates people's moral identity, which in turn increases ethical behaviour. As such, having a strong moral identity does not necessarily mean that people will act ethically in every situation (Aquino et al. 2009). 
Military research on moral identity has focused on the link between leadership and moral identity. In a Norwegian naval cadet sample, moral identity was positively related to peer ratings of transformational leadership and negatively related to peer ratings of passive-avoidant leadership. Transformational leaders inspire their followers to put the common cause or vision ahead of their own interests, whereas passive-avoidant leaders refrain from making active decisions and rectify errors only after they have occurred (Olsen et al. 2006). Other military research has examined the link between moral identity, ethical leadership, and ethical behaviour. Canadian defense personnel who had stronger moral identities and who saw their leaders as being more ethical reported lower levels of unethical behaviour (O'Keefe et al. 2019b).

Military researchers based in the Netherlands have examined the relationship between moral identity, leadership, and moral disengagement (de Graaff et al. 2020). Moral disengagement refers to psychological maneuvers people use to disengage their moral standards so they do not feel guilty when they act in ways inconsistent with these standards (Bandura 1999). Dutch military personnel who served in Afghanistan were interviewed regarding their operational experiences. Researchers then coded the number of times they discussed themes related to moral identity, moral disengagement, and moral dilemmas. Greater awareness of moral issues was related to more justifications for one's actions. This finding is notable because justifications are a form of moral disengagement. Interestingly, military leaders who served in Afghanistan tended to discuss moral identity more frequently than subordinates (de Graaff et al. 2020).

\section{Malevolent Traits and Ethical Behaviour}

Malevolent traits compose the dark triad personality traits and sociopolitical attitudes (Lindén et al. 2019). The dark triad was coined by Paulhus and Williams (2002) to refer to Machiavellianism, narcissism, and psychopathy. A Machiavellian personality is characterized by the manipulation of others and a belief that the ends justify the means; a narcissistic personality is overly motivated by self-concern and grandiosity; and a psychopathic personality refers to having a tendency to violate the rights of others and as lacking guilt and empathy. In addition to the three dark traits described above, researchers have examined two main sociopolitical attitudes: rightwing authoritarianism (RWA) and social dominance orientation (SDO). RWA refers to a personality that tends to submit to authority, that values tradition, and that is willing to support aggression toward people who do not follow expectations and norms (Altemeyer 1981; Whitley 1999). Social dominance orientation refers to "one's degree of preference for inequality among social groups" (Pratto et al. 1994, p. 741). Both RWA and SDO predict prejudice toward outgroup members, such as homosexuals (Whitley 1999).

Researchers have found that within the five dark traits (i.e., Machiavellianism, narcissism, psychopathy, social dominance orientation, and right-wing authoritarianism) an underlying core predicted warzone ethical attitudes, organizational ethical behaviour, and self-reported ethical behaviour in a warzone (Lindén et al. 2019). This finding is noteworthy because it suggests that it might be more effective for 
organizations to use this core of darkness than using measures of Machiavellianism, narcissism, psychopathy, social dominance orientation, and right-wing authoritarianism when screening at-risk candidates. Some research (Nicol et al. 2007) suggests that military socialization may increase SDO but not RWA. Officer cadets enrolled in a Canadian military college reported higher levels of SDO over time. Interestingly, people who applied to be in the military had lower levels of SDO than civilians who did not apply to join the military. Taken together, these findings suggest that increases in SDO among military cadets are attributed to socialization rather than individuals high in SDO selecting to enroll in the military.

\section{Situational}

Despite the importance of individual factors, people can be placed in situations where extraneous factors override their preferences. The context in which a decision must be made influences the ethical decision-making process. Many situational factors can affect ethical decision-making (Messervey et al., 2021; Messervey and Peach 2014; and for a review see Bradley and Tymchuk 2013, 2016; and Messervey 2013). In this chapter two key examples of situational risk factors are discussed: anger and sleep deprivation. Other examples include combat (Wilk et al. 2013) and other stressful conditions (Shalvi et al. 2012), anonymity (Watson 1973), and a desire to minimize risk of harm to military personnel on operations (Choi and Bowles 2007).

Combat experience is an ethical risk factor specific to military operations. Combat experience can include fighting, killing others, witnessing atrocities, threats to one's safety, and exposure to the dead and injured (Wilk et al. 2013). The frequency of various types of combat experience can vary by deployment and operation. American soldiers deployed to Iraq in 2007 most frequently reported the combat experiences of knowing someone who was killed or injured, seeing dead bodies, and working in mined areas. Among a Canadian Armed Forces sample, personnel who recently served in Afghanistan most frequently experienced hostility from the local population (Sudom et al. 2016). Combat experiences, like the ones experienced by US and Canadian military personnel, can lead to feelings of anger (Reyes and Hicklin 2005), and combat experiences and anger are related to ethical behaviour (MHAT IV 2006; Wilk et al. 2013). Researchers found that anger along with disgust were the most common emotions Dutch military personnel cited when describing morally challenging situations on deployment (de Graaff et al. 2015). As mentioned above, moreover, US soldiers who felt angry were more likely than those who did not to report engaging in unethical behaviour, such as kicking and hitting noncombatants and damaging property when it was not necessary (MHAT IV 2006).

\section{Sleep Deprivation}

Fatigue and sleep deprivation negatively affect most types of decision-making, from maintaining vigilance to working-memory tasks that require manipulating information using short-term memory (Lim and Dinges 2010). Sleep deprivation not only 
impairs decision-making in general but can also affect ethical decision-making. In one study, sleep-deprived military students who were taking part in a training exercise were instructed to fire upon realistic-looking dummies. When the target of the exercise turned out to be real people, $59 \%$ of the students tried to fire their weapons in response to an order, even though it violated the LOAC (Larsen 2001).

Fatigue can affect all four components of the ethical decision-making process: (1) moral awareness, (2) moral judgment, (3) intentions to act morally, and (4) moral action (see Rest 1986, for more information on the four components of ethical decision-making). When people are tired, they are less likely to be aware of moral issues. The day following daylight savings time, people are less likely to search moral topics (as measured by Google searches) and to notice moral content in hypothetical moral scenarios (Barnes et al. 2015). Likewise, people are more likely to make poorer moral judgments when they are tired, such as emotionally charged moral judgments (Killgore et al. 2007). Mental fatigue has been found to be related to lowered ethical intentions. A study showed that people experiencing higher levels of sexual desires had greater intentions to engage in infidelity when they were mentally fatigued than those who were not mentally fatigued in a hypothetical scenario (McIntyre et al. 2015). Moreover, when people are tired, they may be tempted to cheat (Barnes et al. 2011) and voluntarily engage in behaviours that violate organizational expectations and threaten the health of an organization (Christian and Ellis 2011).

Good leadership is related to ethical conduct (Kaptein 2008; O'Keefe et al. 2018); however, sleep deprivation can also negatively impact leaders. A Norwegian study found that sleep-deprived military officers were less likely to demonstrate transformative leadership and more likely to show signs of passive-avoidant leadership (Olsen et al. 2016). Naval officer cadets were also less able to anticipate moral problems in a simulated naval operation when they were sleep-deprived (Olsen et al. 2013). Other researchers have found that sleep deprivation in leaders leads to lower perceptions of charisma among followers (Barnes et al. 2016).

\section{Organizational}

Like situational factors, organizational ethical risk factors are external influences that can shape a person's behaviour and ethical decision-making; however, organizational factors are directly related to the organization in which a person is employed. A considerable amount of research has examined the impact of the ethical climate and culture of an organization as well as the influence of ethical leadership on ethical behaviour. Other examples of organizational ethical risk factors include ethos (Fotaki et al. 2020), role expectations (Kelman and Hamilton 1989), and norms (Gino et al. 2009).

\section{Ethical Climate and Culture}

Ethical climate refers to "the shared perception of what is correct behavior, and how ethical situations should be handled in an organization" (Victor and Cullen 1987, 
p. 51). Much of the research related to ethical work climate began with Victor and Cullen. They proposed different climate types that describe the atmosphere within an organization that people consider when dealing with an ethical issue. Five climate types have emerged from their work: (1) instrumental/self-interested - i.e., decisions are made with a focus on the interests of the organization or the individual person; (2) caring - i.e., consideration is centered on a concern for others; (3) rules -i.e., decisions follow the organization's rules; (4) independence - i.e., decisions are based on the person's own ethics and principles; and, (5) law and code - i.e., decisions follow the laws of society.

A significant amount of research (for reviews see Kish-Gephart et al. 2010 and Martin and Cullen 2006) has focused on the outcomes of ethical climate in organizations, and more specifically on the relationship with ethical and unethical behaviour. The ethical climate of organizations has been shown to influence ethical decision-making (Verbeke et al. 1996), ethical behaviour (Shacklock et al. 2013), engagement in counterproductive workplace behaviours (e.g., stealing; Weber et al. 2003), and unethical behaviour (Peterson 2002). Research by Shacklock et al. (2013) found that the perception of the ethical climate in an organization was related to resistance toward a hypothetical unethical situation. Specifically, participants who had a positive perception of their ethical work climate had a heightened sense of selfefficacy; thus, when presented with unethical decisions, they were more able to resist. It has also been found that the effect of ethical climate on ethical behaviour can be bolstered at the work unit level (Arnaud and Schminke 2012). Ethical climate affects ethical behaviour when the work unit has a strong shared belief in their ability to behave ethically (i.e., collective ethical efficacy).

A study with Canadian Army personnel (O'Keefe 2006) examined the relationships between ethical climate, SDO, RWA, and unethical behaviour. This research found that a rules-based ethical climate moderated the relationship between SDO and unethical behaviour. When the climate was perceived to be a strong rules-based climate, Army personnel with a low SDO reported less past unethical behaviour and lower likelihood of engaging in future unethical behaviour. While much of the remaining research on the influence of ethical climate on ethical and unethical behaviour has been conducted with nonmilitary samples, it is evident that ethical climate is an important component of military organizations. Using a military and civilian sample from the Canadian Armed Forces and the Department of National Defence, Dursun (2004) identified important gaps between participants' perceptions of ethical climate between "the way things are" in the organization and individual values regarding "the way things ought to be." As well, Weber and Gerde (2011) have looked at the influence of various organizational factors on the ethical climate of military organizations. Their research suggests that instrumental and caring climates were more prevalent in units with higher risk levels (i.e., in terms of consequences of mission failure), environmental uncertainty, and more task interdependence. While not directly related to ethical behaviour, these results have implications for communications from leadership and also for ethics training (Weber and Gerde 2011). Knowing the ethical climate of a unit should help target the 
messaging and content of communications and training with respect to ethical and unethical behaviour.

Ethical culture refers to "a subset of organizational culture, representing a multidimensional interplay among various formal and informal systems of behavioral control that are capable of promoting either ethical or unethical behavior" (Trevino et al. 1998, p. 451). Whereas ethical climate focuses on the perceptions of those within the organization about handling an ethical dilemma, ethical culture is related to the conditions that exist within the organization that promote ethical behaviour. In line with this, Kaptein (2007) developed the Corporate Ethical Virtue model and defined corporate ethical virtues as "the organizational conditions for ethical conduct" that "reflect the capacity of an organization to stimulate ethical conduct of employees" (p. 924). According to this model, an organization can target solutions for specific weaknesses by understanding the conditions that influence ethical behaviour and identifying potential weak spots in these conditions (Kaptein 2011a).

Like ethical climate, the outcomes of ethical culture in organizations have been well researched. Ethical culture is related to employee responses to observed wrongdoings (e.g., inaction, confrontation, whistleblowing; Kaptein 2011b), unethical behaviour (Kaptein 2011a), and ethical strain (i.e., the stress resulting from dealing with ethical dilemmas; Huhtala et al. 2011). Kaptein (2011a) found that the majority of the dimensions of ethical culture mentioned above were negatively related to unethical behaviour across multiple organizations. Moreover, when observing wrongdoings, the dimensions of ethical culture have been shown to be positively related to intentions to intervene, whether directly to a superior or indirectly via an ethics hotline (Kaptein 2011b).

Research has also shown that ethical culture is strongly connected to ethical leadership (Schaubroeck et al. 2012). Using a sample of US soldiers, Schaubroeck and colleagues found that ethical leadership and ethical culture were positively related at each level of the organization. Moreover, higher level ethical leadership trickled down to positively impact both lower level ethical leadership and also ethical culture. This trickle down of ethical leadership to ethical culture had a positive influence on followers' beliefs in their own ability to act ethically (i.e., moral efficacy) and ethical behaviour, as well as a decrease in unethical behaviour. Ethical leadership is believed to be one of the most influential factors on ethical culture in organizations (Neubert et al. 2009; Schminke et al. 2005) and a strong predictor of the ethical behaviour of people within the organization.

\section{Ethical Leadership}

Leadership plays an important role in promoting ethical behaviour and responding to ethical risk situations (Bradley and Tymchuk 2013, 2016; Olsen et al. 2010). Ethical leadership is defined as "the demonstration of normatively appropriate conduct through personal actions and interpersonal relationships, and the promotion of such conduct to followers through two-way communication, reinforcement, and decision-making" (Brown et al. 2005, p. 120). Using a social learning perspective, Brown and colleagues argue that ethical conduct and behaviour is transferred from leaders to followers via role modeling, and research within a military context has shown that ethical leadership at one level often trickles down to influence ethical 
culture and ethical leadership at more junior levels of the organization (O'Keefe et al. 2019a; Schaubroeck et al. 2012). Moreover, Mayer et al. (2009, 2010) have shown that ethical leadership at higher levels is negatively associated with employee misconduct and deviance, such as taking property from work, damaging property, and deliberately breaking rules.

A significant amount of research has examined the various outcomes of ethical leadership, including willingness to engage in internal whistleblowing (Mayer et al. 2013), employee misconduct (Mayer et al. 2010), workplace deviance (Mayer et al. 2009), and unethical behaviour intentions (O'Keefe et al. 2018). Research with Canadian defense personnel (O'Keefe et al. 2018) found that those who report that their leaders and coworkers act ethically were more likely to engage in behaviours that went above and beyond their regular duties (i.e., organizational citizenship behaviours) and also reported higher levels of ethical intentions (i.e., the likelihood of engaging in ethical behaviour). On the other hand, experiencing bad leadership has been linked to unethical behaviour in military personnel. In a study examining the relationship between leadership and ethical outcomes among US soldiers serving in Iraq, Hannah et al. (2013) found that abusive leadership decreased soldier's moral courage and identification with the organizations' values, which in turn was related to an increase in mistreating noncombatants and a decrease in intentions to report others' unethical behaviour.

\title{
Summary
}

Understanding military ethical behaviour has been a growing field since the Vietnam War. Research has focused on two main areas: (1) battlefield ethics and (2) ethical risk factors. Battlefield ethics encompasses battlefield ethical attitudes, intentions to act ethically, willingness to report peers who violate military laws and standards, and behaviour on operations. Ethical risk factors include individual, situational, and organizational differences that can increase the likelihood of military personnel engaging in unethical behaviour. Individual differences include having a strong moral identity and having malevolent traits, such as psychopathy, narcissism, and right-wing authoritarian tendencies. Situational risk factors include sleep deprivation and combat experiences that can lead to feelings of anger. Organizational factors include having strong ethical leadership and a strong ethical climate and culture.

\section{Cross-References}

\author{
Leadership in Extremis \\ - Military Leader and Leadership Development \\ - Military Profession \\ - Military Training, Education, and Socialization \\ - What is Military Leadership?
}




\section{References}

Altemeyer, B. (1981). Right-wing authoritarianism. University of Manitoba Press.

Aquino, K., Freeman, D., Reed, A., II, Lim, V. K., \& Felps, W. (2009). Testing a social-cognitive model of moral behavior: The interactive influence of situations and moral identity centrality. Journal of Personality and Social Psychology, 97(1), 123-141.

Aquino, K., \& Reed, A., II. (2002). The self-importance of moral identity. Journal of Personality and Social Psychology, 83(6), 1423-1440.

Arnaud, A., \& Schminke, M. (2012). The ethical climate and context of organizations: A comprehensive model. Organization Science, 23(6), 1767-1780.

Bandura, A. (1999). Moral disengagement in the perpetration of inhumanities. Personality and Social Psychology Review, 3(3), 193-209.

Barnes, C. M., Guarana, C. L., Nauman, S., \& Kong, D. T. (2016). Too tired to inspire or be inspired: Sleep deprivation and charismatic leadership. Journal of Applied Psychology, 101(8), 1191-1199.

Barnes, C. M., Gunia, B. C., \& Wagner, D. T. (2015). Sleep and moral awareness. Journal of Sleep Research, 24(2), 181-188.

Barnes, C. M., Schaubroeck, J., Huth, M., \& Ghumman, S. (2011). Lack of sleep and unethical conduct. Organizational Behavior and Human Decision Processes, 115(2), 169-180.

Baumeister, R. F., \& Alghamdi, N. G. (2015). Role of self-control failure in immoral and unethical actions. Current Opinion in Psychology, 6, 66-69.

Beckham, J. C., Feldman, M. E., \& Kirby, A. C. (1998). Atrocities exposure in Vietnam combat veterans with chronic posttraumatic stress disorder: Relationship to combat exposure, symptom severity, guilt, and interpersonal violence. Journal of Traumatic Stress, 11(4), 777-785.

Blanc, J. R. S., Warner, C. H., Ivey, G. W., \& Messervey, D. L. (2018). Association between unethical battlefield conduct and mental health: Implications for leaders and ethical risk assessments. Psychology of Violence, 8(2), 250-258.

Bradley, J. P., \& Tymchuk, S. P. (2013). Assessing and managing ethical risk in defence. Canadian Military Journal, 13(4), 6-16.

Bradley, J. P., \& Tymchuk, S. P. (2016). Managing ethical risk in the Canadian Armed Forces. In S. Belanger \& D. Lagace-Roy (Eds.), Military operations and the mind: War ethics and solders' well-being (pp. 71-119). Montreal: McGill-Queen's University Press.

Breslau, N., \& Davis, G. C. (1987). Posttraumatic stress disorder: The etiologic specificity of wartime stressors. American Journal of Psychiatry, 144, 578-583.

Brown, M. E., Trevino, L. K., \& Harrison, D. A. (2005). Ethical leadership: A social learning perspective for construct development and testing. Organizational Behaviour and Human Decision Processes, 97, 117-134.

Choi, J. K., \& Bowles, S. (2007). The coevolution of parochial altruism and war. Science, 318(5850), 636-640. https://doi.org/10.1126/science.1144237.

Christian, M. S., \& Ellis, A. P. (2011). Examining the effects of sleep deprivation on workplace deviance: A self-regulatory perspective. Academy of Management Journal, 54(5), 913-934.

Currier, J. M., Holland, J. M., Jones, H. W., \& Sheu, S. (2014). Involvement in abusive violence among Vietnam veterans: Direct and indirect associations with substance use problems and suicidality. Psychological Trauma: Theory, Research, Practice, and Policy, 6(1), 73-82.

De Graaff, M. C., Giebels, E., \& Verweij, D. E. (2020). On moral grounds: Moral identity and moral disengagement in relation to military deployment. Military Psychology, 32(4), 363-375.

De Graaff, M. C., Schut, M., Verweij, D. E. M., Vermetten, E., \& Giebels, E. (2015). Emotional reactions and moral judgment: The effects of morally challenging interactions in military operations. Ethics \& Behavior, 26(1), 14-31.

Dennis, P. A., Dennis, N. M., Van Voorhees, E. E., Calhoun, P. S., Dennis, M. F., \& Beckham, J. C. (2017). Moral transgression during the Vietnam War: A path analysis of the psychological impact of veterans' involvement in wartime atrocities. Anxiety, Stress, \& Coping, 30(2), 188201. 
Dursun, S. (2004, October 26-28). Individual values and ethical climate: An empirical study of Canadian Forces [Paper presentation]. Brussels. Retrieved from http://www.imta.info/ PastConferences/Presentations_v2.aspx?Show $=2004$

Fiske, A. P., \& Rai, T. S. (2015). Virtuous violence: Hurting and killing to create, sustain, end, and honor social relationships. Cambridge University Press.

Fontana, A., \& Rosenheck, R. (1993). A causal model of the etiology of war-related PTSD. Journal of Traumatic Stress, 6(4), 475-500.

Fotaki, M., Lioukas, S., \& Voudouris, I. (2020). Ethos is destiny: Organizational values and compliance in corporate governance. Journal of Business Ethics, 166(1), 19-37.

Gino, F., Ayal, S., \& Ariely, D. (2009). Contagion and differentiation in unethical behavior: The effect of one bad apple on the barrel. Psychological Science, 20(3), 393-398.

Hannah, S. T., \& Avolio, B. J. (2010). Moral potency: Building the capacity for character-based leadership. Consulting Psychology Journal: Practice and Research, 62(4), 291-310.

Hannah, S. T., Avolio, B. J., \& May, D. R. (2011). Moral maturation and moral conation: A capacity approach to explaining moral thought and action. Academy of Management Review, 36(4), 663685.

Hannah, S. T., Schaubroeck, J. M., Peng, A. C., Lord, R. G., Trevino, L. K., Kozlowski, S. W. J., Avolio, B. J., Dimotakis, N., \& Doty, J. (2013). Joint influences of individual and work unit abusive supervision on ethical intentions and behaviors: A moderated mediation model. Journal of Applied Psychology, 98, 579-592.

Hertz, S. G., \& Krettenauer, T. (2016). Does moral identity effectively predict moral behavior? A meta-analysis. Review of General Psychology, 20(2), 129-140.

Hiley-Young, B., Blake, D. D., Abueg, F. R., Rozynko, V., \& Gusman, F. D. (1995). Warzone violence in Vietnam: An examination of premilitary, military, and postmilitary factors in PTSD in-patients. Journal of Traumatic Stress, 8(1), 125-141.

Holowka, D. W., Wolf, E. J., Marx, B. P., Foley, K. M., Kaloupek, D. G., \& Keane, T. M. (2012). Associations among personality, combat exposure and wartime atrocities. Psychology of Violence, 2(3), 260-272.

Huhtala, M., Feldt, T., Lamsa, A., Mauno, S., \& Kinnunen, U. (2011). Does the ethical culture of organisations promote managers' occupational well-being? Investigating indirect links via ethical strain. Journal of Business Ethics, 101, 231-247.

International Committee of the Red Cross. (2004). What is international humanitarian law? Retrieved from https://www.icrc.org/en/doc/assets/files/other/what_is_ihl.pdf

Jennings, P. L., Mitchell, M. S., \& Hannah, S. T. (2015). The moral self: A review and integration of the literature. Journal of Organizational Behavior, 36(S1), S104-S168.

Kaptein, M. (2007). Developing and testing a measure for the ethical culture of organizations: The corporate ethical virtues model. Journal of Organizational Behavior, 29, 923-947.

Kaptein, M. (2008). Developing a measure of unethical behavior in the workplace: A stakeholder perspective. Journal of Management, 34, 978-1008.

Kaptein, M. (2011a). Understanding unethical behaviour by unraveling ethical culture. Human Relations, 64, 843-869.

Kaptein, M. (2011b). From inaction to external whistleblowing: The influence of the ethical culture of organizations on employee responses to observed wrongdoing. Journal of Business Ethics, 98, 513-530.

Kelman, H. C., \& Hamilton, V. L. (1989). Crimes of obedience: Toward a social psychology of authority and responsibility. New Haven: Yale University Press.

Killgore, W. D., Killgore, D. B., Day, L. M., Li, C., Kamimori, G. H., \& Balkin, T. J. (2007). The effects of 53 hours of sleep deprivation on moral judgment. Sleep, 30(3), 345-352.

King, D. W., King, L. A., Gudanowski, D. M., \& Vreven, D. L. (1995). Alternative representations of war zone stressors: Relationships to posttraumatic stress disorder in male and female Vietnam veterans. Journal of Abnormal Psychology, 104(1), 184-196. 
Kish-Gephart, J. J., Harrison, D. A., \& Trevino, L. K. (2010). Bad apples, bad cases, and bad barrels: Meta-analytic evidence about sources of unethical decisions at work. Journal of Applied Psychology, 95, 1-31.

Kraus, D. S. (2013). Morally injurious symptomatology: A qualitative examination of the NVVRS. Theses and Dissertations. 334. Pepperdine University.

Kulka, R. A., Schlenger, W. E., Fairbank, J. A., Hough, R. L., Jordan, B. K., Marmar, C. R., \& Weiss, D. S. (1988). Contractual report of findings from the National Vietnam veterans' readjustment study. Research Triangle Park: Research Triangle Institute.

Larsen, R. P. (2001). Decision making by military students under severe stress. Military Psychology, 13(2), 89-98.

Laufer, R. S., Brett, E., \& Gallops, M. S. (1985). Symptom patterns associated with posttraumatic stress disorder among Vietnam veterans exposed to war trauma. American Journal of Psychiatry, 142, 1304-1311.

Laufer, R. S., Gallops, M. S., \& Frey-Wouters, E. (1984). War stress and trauma: The Vietnam veteran experience. Journal of Health and Social Behavior, 65-85.

Lim, J., \& Dinges, D. F. (2010). A meta-analysis of the impact of short-term sleep deprivation on cognitive variables. Psychological Bulletin, 136(3), 375-389.

Lindén, M., Björklund, F., Bäckström, M., Messervey, D., \& Whetham, D. (2019). A latent core of dark traits explains individual differences in peacekeepers' unethical attitudes and conduct. Military Psychology, 31(6), 499-509.

MacNair, R. M. (2002). Perpetration-induced traumatic stress in combat veterans. Peace and Conflict: Journal of Peace Psychology, 8(1), 63-72.

Martin, K. D., \& Cullen, J. B. (2006). Continuities and extensions of ethical climate theory: A metaanalytic review. Journal of Business Ethics, 69(2), 175-194.

Mayer, D. M., Kuenzi, M., Greenbaum, R., Bardes, M., \& Salvador, R. (2009). How long does ethical leadership flow? Test of trickle-down model. Organizational Behaviour and Human Decision Processes, 108, 1-13.

Mayer, D. M., Kuenzi, M., \& Greenbaum, R. L. (2010). Examining the link between ethical leadership and employee misconduct: The mediating role of ethical climate. Journal of Business Ethics, 95(7), 7-16.

Mayer, D. M., Nuromohamed, S., Trevino, L. K., Shapiro, D. L., \& Schminke, M. (2013). Encouraging employees to report unethical conduct internally: It takes a village. Organizational Behaviour and Human Decision Processes, 121, 89-103.

McIntyre, J. C., Barlow, F. K., \& Hayward, L. E. (2015). Stronger sexual desires only predict bold romantic intentions and reported infidelity when self-control is low. Australian Journal of Psychology, 67(3), 178-186.

Mental Health Advisory Team (MHAT-IV). Operation Iraqi Freedom 05-07 (Nov 17, 2006). Retrieved from https://ntrl.ntis.gov/NTRL/dashboard/searchResults/titleDetail/PB2010103335. xhtml

Mental Health Advisory Team (MHAT-V). Operation Iraqi Freedom 06-08 (Feb 14, 2008). Retrieved from https://armymedicine.health.mil/-/media/Files/ArmyMedicine/Reports/ Redacted1MHATV4FEB2008Overview. ashxla=en\&hash=819D0D68C4D89820AC 949016B454DDA9C1FD09B2507382614CB90D10D62CA7B1

Messervey, D. L. (2013). What drives moral attitudes and behavior? [Director General Military Personnel Research and Analysis Technical Report 2013-003]. Ottawa: Defence Research and Development Canada.

Messervey, D. L., \& Lavergne, K. (2016). The re-development of the 2014/2015 Defence Ethics Survey (Director General Military Personnel Research and Analysis Scientific Report DRDCRDDC-2016-R111). Ottawa: Defence Research and Development Canada.

Messervey, D. L., \& Peach, J. (2014). Battlefield ethics: What influences ethical behavior on operations. In G. W. Ivey, K. Sudom, W. H. Dean, \& M. A. Tremblay (Eds.), The human dimensions of operations: A personnel research perspective (pp. 83-101). Kingston: Canadian Defence Academy Press. 
Messervey, D. L., Dean,W. H., Nelson, E. A., \& Peach, J. M. (2021). Making moral decisions under stress: A revised model for defence. Canadian Military Journal, 21(2), 38-47.

Neubert, M. J., Carkson, D. S., Kacmar, K. M., Roberts, J. A., \& Chonko, L. B. (2009). The virtuous influence of ethical leadership behaviour: Evidence from the field. Journal of Business Ethics, 41, 313-326.

Nicol, A. A., Charbonneau, D., \& Boies, K. (2007). Right-wing authoritarianism and social dominance orientation in a Canadian military sample. Military Psychology, 19(4), 239-257.

O'Keefe, D. F. (2006). Assessing the moderating effects of ethical climate on the relation between social dominance orientation / right-wing authoritarianism and self-reported unethical behaviour. Unpublished doctoral dissertation, University of Guelph.

O'Keefe, D. F., Messervey, D., \& Squires, E. C. (2018). Promoting ethical and prosocial behavior: The combined effect of ethical leadership and coworker ethicality. Ethics \& Behavior, 28(3), 235-260.

O'Keefe, D. F., Howell, G. T., \& Squires, E. C. (2019a). Ethical leadership begets ethical leadership: Exploring situational moderators of the trickle-down effect. Ethics \& Behavior. Advance online publication. https://doi.org/10.1080/10508422.2019.1649676.

O'Keefe, D. F., Peach, J. M., \& Messervey, D. L. (2019b). The combined effect of ethical leadership, moral identity, and organizational identification on workplace behavior. Journal of Leadership Studies, 13(1), 20-35.

Olsen, O. K., Eid, J., \& Johnsen, B. H. (2006). Moral behavior and transformational leadership in Norwegian naval cadets. Military Psychology, 18(Sup1), S37-S56.

Olsen, O. K., Eid, J., \& Larsson, G. (2010). Leadership and ethical justice behavior in a high moral intensity operational context. Military Psychology, 22(Suppl), S137-S156. https://doi.org/10. 1080/08995601003644437.

Olsen, O. K., Pallesen, S., \& Espevic, R. (2013). The impact of partial sleep deprivation on military naval officers' ability to anticipate moral and tactical problems in a simulated maritime combat operation. International Maritime Health, 64(2), 61-65.

Olsen, O. K., Pallesen, S., Torsheim, T., \& Espevik, R. (2016). The effect of sleep deprivation on leadership behavior in military officers: An experimental study. Journal of Sleep Research, 25(6), 683-689.

Paulhus, D., \& Williams, K. (2002). The dark triad of personality: Narcissism, Machiavellianism, and psychopathy. Journal of Research in Personality, 36, 556-563.

Peterson, D. K. (2002). The relationship between unethical behavior and the dimensions of the ethical climate questionnaire. Journal of Business Ethics, 41, 313-326.

Pratto, F., Sidanius, J., Stallworth, L. M., \& Malle, B. F. (1994). Social dominance orientation: A personality variable predicting social and political attitudes. Journal of Personality and Social Psychology, 67(4), 741-763.

Rest, J. R. (1986). Moral development: Advances in research and theory. New York: Praeger.

Reyes, V. A., \& Hicklin, T. A. (2005). Anger in the combat zone. Military Medicine, 170(6), 483487.

Schaubroeck, J., Hannah, S. T., Avolio, B. J., Doty, J., Kozlowski, S., Lord, R., \& Trevino, L. (2010). Excellence in Character and Ethical Leadership (EXCEL) study (Center for the Army Profession and Ethic Technical Report No. 2010-01). West Point, NY: U.S. Army.

Schaubroeck, J., Hannah, S. T., Avolio, B. J., Kozlowski, S., Lord, R., Trevino, L. K., Dimotakis, N., \& Peng, A. C. (2012). Embedding ethical leadership within and across organization levels. Academy of Management Journal, 55, 1053-1078. https://doi.org/10.5465/ainj.2011.0064.

Schminke, M., Ambrose, M. L., \& Neubaum, D. O. (2005). The effect of leader moral development on ethical climate and employee attitudes. Organizational Behavior and Human Decision Processes, 97(2), 135-151.

Schut, M., De Graaff, M. C., \& Verweij, D. (2015). Moral emotions during military deployments of Dutch forces: A qualitative study on moral emotions in intercultural interactions. Armed Forces \& Society, 41(4), 616-638. 
Shacklock, A., Manning, M., \& Hort, L. (2013). Self-efficacy as an intervening variable between ethical work climate and decision making. e-Journal of Social \& Behavioral Research in Business, 4(2), 1-13.

Shalvi, S., Eldar, O., \& Bereby-Meyer, Y. (2012). Honesty requires time (and lack of justifications). Psychological Science, 23(10), 1264-1270.

Shaw, D. M., Churchill, C. M., Noyes, R., Jr., \& Loeffelholz, P. L. (1987). Criminal behavior and post-traumatic stress disorder in Vietnam veterans. Comprehensive Psychiatry, 28(5), 403-411.

Sudom, K., Watkins, K., Born, J., \& Zamorski, M. (2016). Stressors experienced during deployment among Canadian Armed Forces personnel: Factor structure of two combat exposure scales. Military Psychology, 28(5), 285-295.

Therrien, M. E., \& Messervey, D. L. (2019). Ethical attitudes and intentions on the battlefield: Empirical evidence from the Human Dimensions of Operations Survey (Defence Research and Development Canada Scientific Report DRDC-RDDC-2019-R185). Ottawa: Defence Research and Development Canada.

Trevino, L. K., Butterfield, K. D., \& McCabe, D. L. (1998). The ethical context in organizations: Influences on employee attitudes and behaviors. Business Ethics Quarterly, 8, 447-746.

United Nations Office on Genocide Prevention and the Responsibility to Protect. (n.d.). Prevention. Retrieved from https://www.un.org/en/genocideprevention/prevention.shtml

Verbeke, W., Ouwerkerk, C., \& Peelen, E. (1996). Exploring the contextual and individual factors on ethical decision making of salespeople. Journal of Business Ethics, 15, 1175-1187.

Victor, B., \& Cullen, J. B. (1987). A theory and measure of ethical climates in organizations. Research in Corporate Social Performance and Policy, 9, 51-71.

Vila-Vázquez, G., Castro-Casal, C., \& Álvarez-Pérez, D. (2021). Person-organization fit and helping behavior: How and when this relationship occurs. Current Psychology. https://doi.org/ 10.1007/s12144-021-01708-5.

Warner, C. H., Appenzeller, G. N., Mobbs, A., Parker, J. R., Warner, C. M., Grieger, T., \& Hoge, C. W. (2011). Effectiveness of battlefield-ethics training during combat deployment: A programme assessment. The Lancet, 378(9794), 915-924.

Watson, R. I. (1973). Investigating into deindividuation using a cross-cultural survey technique. Journal of Personality and Social Psychology, 25, 342-345.

Weber, J., \& Gerde, V. W. (2011). Organizational role and environmental uncertainty as influences on ethical work climate in military units. Journal of Business Ethics, 100, 595-612.

Weber, J., Kurke, L. B., \& Pentico, D. W. (2003). Why do employees steal? Assessing differences in ethical and unethical employee behavior using ethical work climates. Business \& Society, 42, 359-380.

Whitley, B. E., Jr. (1999). Right-wing authoritarianism, social dominance orientation, and prejudice. Journal of Personality and Social Psychology, 77(1), 126-134.

Wilk, J. E., Bliese, P. D., Thomas, J. L., Wood, M. D., McGurk, D., Castro, C. A., \& Hoge, C. W. (2013). Unethical battlefield conduct reported by soldiers serving in the Iraq war. Journal of Nervous and Mental Disease, 201(4), 259-265.

Wilson, J. P., \& Krauss, G. E. (1980). The Vietnam era stress inventory. Cleveland State University. Wilson, J. P., \& Krauss, G. E. (1983). Posttraumatic stress disorders (PTSD): Collected papers. Cleveland: Cleveland State University.

\section{Further Reading}

Bradley, J. P., \& Tymchuk, S. P. (2013). Assessing and managing ethical risk in defence. Canadian Military Journal, 13(4), 6-16.

Castro, C. A., \& McGurk, D. (2007). Battlefield ethics. Traumatology, 13(4), 24-31. 
Laufer, R. S., Gallops, M. S., \& Frey-Wouters, E. (1984). War stress and trauma: The Vietnam veteran experience. Journal of Health and Social Behavior, 65-85.

Lindén, M., Björklund, F., Bäckström, M., Messervey, D., \& Whetham, D. (2019). A latent core of dark traits explains individual differences in peacekeepers' unethical attitudes and conduct. Military Psychology, 31(6), 499-509.

Messervey, D. L., Dean, W. H., Nelson, E. A., \& Peach, J. M. (2021). Making moral decisions under stress: A revised model for defence. Canadian Military Journal, 21(2), 38-47.

Wilk, J. E., Bliese, P. D., Thomas, J. L., Wood, M. D., McGurk, D., Castro, C. A., \& Hoge, C. W. (2013). Unethical battlefield conduct reported by soldiers serving in the Iraq war. Journal of Nervous and Mental Disease, 201(4), 259-265.

Open Access This chapter is licensed under the terms of the Creative Commons Attribution 4.0 International License (http://creativecommons.org/licenses/by/4.0/), which permits use, sharing, adaptation, distribution and reproduction in any medium or format, as long as you give appropriate credit to the original author(s) and the source, provide a link to the Creative Commons license and indicate if changes were made.

The images or other third party material in this chapter are included in the chapter's Creative Commons license, unless indicated otherwise in a credit line to the material. If material is not included in the chapter's Creative Commons license and your intended use is not permitted by statutory regulation or exceeds the permitted use, you will need to obtain permission directly from the copyright holder.

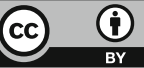

